\title{
In Search of Optimal Distinctiveness: Balancing Conformity and Differentiation via Organizational Learning - Corrigendum
}

\section{Yimei Hu, Huanren Zhang, and Yuchen Gao}

DOI: https://doi.org/10.1017/mor.2021.35; First published online by Cambridge University Press 07 September 2021

In the initial publication of $\mathrm{Hu}$ et al. (2021), formatting errors occurred within several equations throughout the article. The original publication has since been updated to include the correct formatting of each equation.

\section{Reference}

Hu, Y., Zhang, H., \& Gao, Y. 2021. In Search of Optimal Distinctiveness: Balancing Conformity and Differentiation via Organizational Learning. Management and Organization Review, 1-36. doi:10.1017/mor.2021.35. 